\title{
A JUDICIALIZAÇÃO DO DIREITO À ALIMENTAÇÃO ADEQUADA: UMA NOVA DISCUSSÃO ACERCA DA PRESTAÇÃO DOS DIREITOS FUNDAMENTAIS
}

\section{LA JUDICIALIZACIÓN DEL DERECHO A UNA ALIMENTACIÓN ADECUADA: UN NUEVO DEBATE SOBRE LA PRESTACIÓN DE LOS DERECHOS FUNDAMENTALES}

\author{
${ }^{1}$ Marcelo Lessa da Silva \\ ${ }^{2}$ Diogo Oliveira Muniz Caldas
}

\section{RESUMO}

O presente artigo objetivou a análise da possibilidade de judicialização do direito à alimentação adequada através da construção de um novo pensamento, baseado nos processos judiciais de solicitação do cumprimento de direitos fundamentais sociais em face da Administração Pública, necessários à sobrevivência dos solicitantes, levando-se em conta o princípio da igualdade na tutela jurisdicional dos direitos fundamentais. Para tanto, utilizouse do método de pesquisa teórico-dogmática, exploratório e explicativo, adotando-se uma pesquisa jurídica e social de natureza aplicada, com técnica de coleta e análise, documental e bibliográfica. Conclui-se que o direito a alimentação é um direito humano e fundamental reconhecido pelas normas internacionais de direitos humanos e pela constituição federal brasileira. O direito à alimentação é um autêntico e verdadeiro direito fundamental, acionável, exigível e demanda séria e responsável observância. Por isso, deve ser reivindicado como direito e não como caridade, generosidade ou compaixão. Verificou-se a possibilidade de judicialização para se garantir a efetivação do direito à alimentação adequada com base nas decisões dos Tribunais Superiores, inclusive do Supremo Tribunal Federal, que autorizam o bloqueio de valores para assegurar, por exemplo, tratamento médico ou medicamentos como formas de respeitar o princípio da dignidade da pessoa humana e o direito fundamental a vida. Assim, em respeito ao princípio da igualdade onde todos têm os mesmos direitos ao acesso aos bens e serviços considerados essenciais, o direto à alimentação vincula-se de forma semelhante aos direitos à vida, à saúde e a educação, pois são direitos humanos e fundamentais, oriundos do fundamento da dignidade da pessoa humana. De forma acertada, portanto, deve o judiciário apreciar lesão ou ameaça a direito conforme dispõe a constituição federal para garantir o direito humano e fundamental à alimentação adequada.

Palavras-chave: Direito à alimentação adequada, Direitos sociais, Judicialização, Reserva do possível, Mínimo existencial

\section{RESUMEN}

Este artículo tuvo como objetivo examinar la posibilidad de la judicialización del derecho a una alimentación adecuada mediante la construcción de un nuevo pensamiento, basado en procesos judiciales de solicitación del cumplimiento de los derechos sociales fundamentales

\footnotetext{
1 Doutorando em Ciências Jurídicas e Sociais pela Universidad del Museo Argentino. Professor da Pós-graduação em Direito Imobiliário das Universidades Veiga de Almeida. Universidades Veiga de Almeida - UVA, Rio de Janeiro. Brasil - E-mail: marcelolessa.federal@yahoo.com.br

2 Doutor pela Universidade Veiga de Almeida. Professor da Universidade Veiga de Almeida. Universidades Veiga de Almeida - UVA, Rio de Janeiro. Brasil - E-mail: diocaldas@ hotmail.com
} 
contra la Administración Pública, necesaria para la supervivencia de los solicitantes, teniendo en cuenta el principio de igualdad en la protección judicial de los derechos fundamentales. Así, se utilizó el método de la investigación teórica y dogmática, exploratoria y explicativa, tomando una investigación jurídica y social de naturaleza aplicada, con la técnica de recolección y análisis, documental y bibliográfica. Se concluye que el derecho a la alimentación es un derecho humano y fundamental reconocido por las normas internaciona les de derechos humanos y por la constitución federal brasileña. El derecho a la alimentación es un auténtico y genuino derecho fundamental, accionable, exigible y demanda seria y responsable observancia. Se verificó la posibilidad de judicialización para garantizarse la efectivación del derecho a la alimentación adecuada con base en las decisiones de los Tribunales Superiores, inclusive del Supremo Tribunal Federal, que autorizan el bloqueo de valores para asegurar, por ejemplo, tratamiento médico o medicamentos como formas de respetar el principio de la dignidad de la persona humana y el derecho fundamental a la vida. Así, en respeto al principio de la igualdad donde todos tienen los mismos derechos al acceso a los bienes y servicios considerados esenciales, el derecho a la alimentación se vincula de forma semejante a los derechos a la vida, a la salud y la educación, pues son derechos humanos y fundamentales, oriundos del fundamento de la dignidad de la persona humana. De forma acertada, por lo tanto, debe el judicial apreciar lesión o amenaza a derecho conforme dispone la constitución federal para garantizar el derecho humano y fundamental a la alimentación adecuada.

Palabras-claves: Derecho a la alimentación adecuada, Derechos sociales, Judicializaçión, Reserva del posible, Mínimo existencial 


\section{INTRODUÇÃO}

A atual Constituição da República Federativa do Brasil estabelece, em seu artigo $6^{\circ}$, caput, que o direito à alimentação é considerado um direito social (CRFB, 1988). Esses direitos são fundamentais para o dia a dia do cidadão, sendo classificados como liberdades de natureza positiva, que deve ser vinculada na vigência de um Estado Social de Direito, tendo como principal escopo proporcionar uma melhor qualidade de vida aos administrados, principalmente hipossuficientes, perseguindo justiça e igualdade social.

A inclusão do direito à alimentação, pela Emenda Constitucional 64, de 4 de fevereiro de 2010, alçou essa matéria a um inédito grau de importância na história do direito nacional. Entretanto, algumas discussões surgiram na concessão desse direito por parte da União, Estados, Distrito Federal e Municípios como, por exemplo, se os cidadãos podem exigir a prestação desse direito, ao comprovar a necessidade dos alimentos, em ação judicial proposta em face da Administração Pública.

O presente trabalho objetivou a análise da possibilidade de judicialização do direito à alimentação adequada através da construção de um novo pensamento, baseado nos processos judiciais de solicitação do cumprimento de direitos fundamentais sociais, em face da Administração Pública, que são necessários à sobrevivência dos solicitantes, levando-se em conta o princípio da igualdade. A tese central se abarca nas decisões dos Tribunais Superiores, inclusive do Supremo Tribunal Federal, que autorizam o bloqueio de valores para assegurar, por exemplo, tratamento médico ou medicamentos como formas de respeitar o princípio da dignidade da pessoa humana e o direito fundamental a vida. Assim, pela mesma razão por ora levantada, o direto à alimentação vincula-se de forma semelhante aos direitos à vida e à dignidade humana, sendo tão fundamental quanto o direito à saúde para a sobrevivência dos requerentes.

Cabe ressaltar que o direito a alimentação compõe o rol de direitos sociais previsto no ordenamento jurídico internacional dos direitos humanos da qual o Brasil é signatário, como a Declaração Universal dos Direitos Humanos - DUDH, o Pacto Internacional dos Direitos Econômicos, Sociais e Culturais - PIDESC e a Convenção Interamericana de Direitos Humanos, entre outros. E ainda, reconhecido internamente de forma expressa no artigo $6^{\circ}$ da Constituição Federal, podendo, destarte, ser exigido judicialmente, de forma individual ou coletiva, pelos agentes legitimados, pelo ordenamento jurídico, a defender grupos e coletividade, v.g., o Ministério Público, as defensorias, as associações civis e os 
sindicatos, em conformidade com o que determina o artigo $5^{\circ}, \mathrm{XXXV}$, "a lei não excluirá da apreciação do Poder Judiciário lesão ou ameaça a direito".

Para tanto, utilizou-se do método de pesquisa teórico-dogmática, exploratório e explicativo, adotando-se uma pesquisa jurídica e social de natureza aplicada, com técnica de coleta e análise, documental e bibliográfica.

Em um primeiro momento analisou-se questões gerais acerca dos alimentos, sua importância para a manutenção da vida e conceitos básicos, que serão ferramentas fundamentais para o entendimento do estudo. A seguir analisou-se o direito à alimentação adequada sob o prisma dos direitos humanos internacionalmente reconhecidos nos diversos tratados internacionais da qual o Brasil é signatário; na terceira parte o trabalho focou nos argumentos dos quais poderão se valer, requerentes e requeridos, além de uma breve análise das teorias que direcionarão a discussão central. E, Por fim, foram demonstrados argumentos que desaguarão no fundamento da prestação desse direito e que incentivará, cada vez mais, os cidadãos a solicitarem o seu cumprimento por meio do Poder Judiciário.

\section{ASPECTOS GERAIS ACERCA DA IMPORTÂNCIA DOS ALIMENTOS}

Inicialmente deve ser entendida a verdadeira importância da questão alimentar em âmbito nacional e mundial. A necessidade do ser humano em se alimentar, por meio natural ou superficial, é considerado processo essencial para a manutenção de vida daquilo que se é considerado vivo.

Partindo de uma análise da produção de alimentos no cenário brasileiro é delineada uma divisão entre a área rural, que tem sua economia baseada na produção de alimentos e produtos primários; e da área urbana, que basicamente possui sua ordem econômica baseada em relações de comércio. Ademais, a relação entre essas duas regiões é facilmente observada com o consumo dos alimentos, em grande quantidade, produzidos em área rural pelos moradores das áreas classificadas como urbanizadas.

Além do consumo pelo mercado trabalhador, por meio da compra desses alimentos em supermercados, feiras livres, mercearias, entre outros, existe uma camada da população que não possui condições mínimas para consumir o mínimo necessário para a manutenção de sua sobrevivência durante o dia. Isso ocorre não só pela falta de um rendimento mínimo nas mãos do cidadão, mas a uma equação que se completa ao somar o gasto com os serviços essenciais 
(exemplo: fornecimento de água, energia elétrica, etc...) e o severo aumento do preço dos alimentos verificado nos últimos 50 anos.

Para ter uma base de análise, em recente pesquisa realizada pela Food and Agriculture Organization of the United Nations (FAO), entre 1965 e 2015, o preço indexado dos alimentos em termos reais e nominais mais do que triplicaram. Se forem levados em consideração apenas o período entre 2000 e 2014 o mesmo índice indexador saiu de 91.1 para 201.8, ou seja, mais do que o dobro em pouco mais de 10 anos (World Food Situation, 2015). A situação é, ainda, mais alarmante; na sexagésima nona Assembleia Geral das Nações Unidas, ocorrida em 23 de setembro de 2014, ao verificar as metas de desenvolvimento do milênio (Millennium Development Goals - MDG), que devem ser cumpridas até o final de 2015, um dos principais destaques foi o número de pessoas que ainda passam fome no mundo. Aparece na Introdução de publicação preliminar (FAO, IFAD and WFP, 2014):

Despite this progress, however, the number of hungry people in the world is still unacceptably high: at least 805 million people, or one in nine, worldwide do not have enough to eat. Global trends in hunger reduction mask disparities within and among regions. ${ }^{1}$

Para ter uma ideia da crescente dificuldade do acesso aos alimentos no Brasil outra visão que corrobora o aumento no preço dos alimentos é a pesquisa realizada, mensalmente, pelo Departamento do Agronegócio da Federação das Indústrias do Estado de São Paulo (Deagro/Fiesp, 2015). Em sua mais recente pesquisa, datada de julho de 2015, o Índice Geral de Preços ao Consumidor Amplo (IPCA) para bebidas e alimentos, que analisa o aumento ou a queda desses dois tipos de produtos, apontou que nos últimos 12 meses o aumento acumulado já é o maior desde dezembro de 2003.

A pressão nos preços dos alimentos os transforma, cada vez mais, em produtos inalcançáveis por parte da população. Em um país cuja justiça de distribuição equitativa e equilibrada de alimentos parece a cada dia mais distante, muitos brasileiros vivem em situação grave de privação de alimentos, para ser mais preciso, mais de 7 milhões de pessoas passaram por total privação de alimentos, incluindo nesses casos adultos e crianças.(IBGE,2014)

\footnotetext{
${ }^{1}$ Apesar deste progresso, no entanto, o número de pessoas com fome no mundo continua a ser inaceitavelmente elevado : pelo menos 805 milhões de pessoas, ou um em cada nove, em todo o mundo não têm o suficiente para comer. As tendências globais das disparidades máscara de redução da fome dentro e entre regiões.
} 
Por mais que alguns autores indiquem que a época atual é vivenciada por uma transição do pensamento individual para o social, pelo menos no que tange aos alimentos é observado movimento oposto a essa mudança. Cada vez menos pessoas possuem espaços de terras para produzir alimentos, para si e seus familiares, ficando a mercê dos grandes latifundiários e da exploração do agronegócio por grandes multinacionais.

Verificando então que há uma clara falha na política de reforma agrária brasileira para uma melhor distribuição de condições de produção dos alimentos, além da falta de postos de trabalho nos grandes centros conjuntamente com a baixa remuneração que, ao analisar o cenário traçado superficialmente acima, não permite que milhões de cidadãos brasileiros tenham acesso ao mínimo necessário para sua sobrevivência.

\section{DIREITO À ALIMENTAÇÃO ADEQUADA NO PLANO INTERNACIONAL}

No plano internacional, temos dois sistemas de proteção dos direitos humanos, o global e o regional. No sistema global, temos como principais documentos de proteção à alimentação adequada, a Declaração Universal de Direitos Humanos - DUDH de 1948, artigo XXV, $\mathrm{n}^{\mathrm{o}} 1^{2}$ e o Pacto Internacional de Direitos Econômicos, Sociais e Culturais - PIDESC de 1966, artigo 11. ${ }^{3}$ Já no Sistema Regional, destaca-se o Protocolo Adicional da Convenção Interamericana de Direitos Humanos (Pacto de São José da Costa Rica/1969) ${ }^{4}$ em matéria de Direitos Econômicos, Sociais e Culturais, denominado Protocolo de San Salvador (1998). ${ }^{5}$

\footnotetext{
2 Segundo o art. XXV, n. 1 da Declaração Universal de Direitos Humanos: Todo ser humano tem direito a um padrão de vida capazde assegurar-lhe, e a sua família. saúde e bem-estar. inclusive alimentação. vestuário, habitação, cuidados médicos e os serviços sociais indispensáveis, e direito à segurança em caso de desemprego, doença, invalidez, viuvez, velhice ou outros casos de perda dos meios de subsistência emcircunstâncias fora de seu controle. (grifo nosso)

3 Dispõe o artigo 11 do Pacto internacional dos Direitos Econômicos, Sociais e Culturais, adesão feita pelo Brasil em 1992 e promulgado através do decreto no 591 , que:

(1). Os Estados Partes do presente Pacto reconhecemo direito de toda pessoa anível de vida adequado para si próprio e sua família inclusive à alimentação vestimenta e moradia adequadas, assim como a uma melhoria

contínua de suas condições de vida. Os Estados Partes tomarão medidas apropriadas para assegurar a consecução desse direito, reconhecendo, nesse sentido, a importância essencial da cooperação internacional fundada no livre consentimento.

(2). Os Estados Partes do presente pacto, reconhecendo o direito fundamental de toda pessoa de estar protegida contra a fome, adotarão, individualmente e mediante cooperação internacional, as medidas, inclusive programas

concretos, que se façam necessárias para:

a) melhorar os métodos de produção, conservação e distribuiçãode gêneros alimentícios pela plena utilização dos conhecimentos técnicos e científicos, pela difusão de princípios de educação nutricional e pelo aperfeiçoamento ou reforma dos regimes agrários, de maneira que se assegurema exploração e a utilização mais eficazes dos recursos naturais;

b) Assegurar uma repartição eqüitativa dos recursos alimentícios mundiais em relação às necessidades.

levando-se em conta os problemas tanto dos países importadores quanto dos exportadores de gêneros alimentícios. (grifo nosso)

4 Promulgado no Brasil através do Decreto n ${ }^{\circ} 678 / 92$.

5 Promulgado no Brasil através do Decreto no 3.321/99, o Artigo 12 do Protocolo de San Salvador tem como tópico o direitoà alimentação dispondo o seguinte: 1. Toda pessoa tem direito a uma nutrição adequada que assegure a possibilidade de gozar do mais alto nível de

desenvolvimento físico, emocional e intelectual. 2. A fimde tornar efetivo esse direito e de eliminar a desnutrição, os Estados Partes comprometem-se a aperfeiçoar os métodos de produção, abastecimento e distribuição de alimentos, para o que se comprometema promover maior cooperação internacional comvistas a apoiar as políticas nacionais sobreo tema.
} 
Ademais, no plano nacional o direito à alimentação está prevista, direta e expressamente, no caput do artigo $6^{\circ}$ da CRFB, inserida pela emenda Constitucional $\mathrm{n}^{\circ}$ 64/2010, sedimentando toda e qualquer discussão sobre sua proteção constitucional como um direito fundamental. E ainda, pode se encontrar implicitamente presente em alguns outros textos constitucionais, v.g., artigos $1^{\circ}$, III e o artigo $3^{\circ}$, III, IV.

Destarte, a Declaração Universal dos Direitos Humanos - DUDH de 1948, fonte inspiradora do Sistema Internacional Universal de proteção aos direitos humanos, em seu artigo $\mathrm{XXV}, 1$, reconhece o direito à alimentação como um direito humano quando dispõe que todo homem tem direito a um padrão de vida capaz de assegurar a si e sua família, saúde e bem estar, incluindo a alimentação, vestuário, habitação, cuidados médicos e os serviços sociais indispensáveis, e ainda, direito à segurança em caso de desemprego, doença, invalidez, viuvez, velhice ou outros casos de perda dos meios de subsistência em situações fora de seu controle. Desta forma, a Declaração Universal reconhece que o direito a um padrão de vida capaz de assegurar a si e sua família, saúde e bem estar, só será alcançável se os demais direitos elencados forem respeitados e garantidos, principalmente no que tange a uma alimentação adequada.

O PIDESC apresenta elenco de direitos mais amplos e detalhados que os elencados nos da Declaração, sendo o primeiro instrumento jurídico no âmbito das Nações Unidas a detalhar os chamados direitos de segunda dimensão; os econômicos, sociais e culturais, consignando que os Estados-partes se obrigam a implementá-los em seus territórios, dispensando a eles a mesma importância dos direitos civis e políticos, direitos de primeira dimensão. Desta forma, fortalece a característica da não hierarquia entre os direitos humanos de primeira e segunda dimensão, reconhecendo as necessárias características da indivisibilidade, inter-relacionariedade e interdependência dos direitos humanos.

A finalidade precípua do Pacto é a de estabelecer as condições sociais, econômicas e culturais para a existência de uma vida digna. Trata-se, na essência, de conferir proteção aos direitos humanos, que surgem e se desenvolvem em obediência a um núcleo existencial, a dignidade da pessoa humana.

Destarte, o direito a alimentação é um direito humano reconhecido pelas normas internacionais de direitos humanos, tanto pelo sistema universal quanto no sistema regional.

Apesar da frequente afirmação da comunidade internacional para a importância do pleno respeito ao direito à alimentação adequada necessária à garantia da dignidade da pessoa humana (fundamento nuclear dos direitos humanos), permanece a existência de um abismo preocupante entre as normas fixadas no ordenamento jurídico internacional dos direitos 
humanos, v.g., o artigo 11 do Pacto Internacional dos Direitos Econômicos, Sociais e Culturais (PIDESC), e a situação reinante em muitas regiões do mundo.

É inegável a necessidade de alimentos em quantidades suficientes para manutenção e desenvolvimento da saúde e da própria vida. Portanto, a alimentação é um direito que compõe o núcleo essencial dos direitos humanos, devendo o seu acesso ser garantido por meios próprios ou por organismos internacionais ou nacionais, estatais ou não estatais.

Cabe ressaltar que a violação do direito humano à alimentação adequada pode ocorrer de duas formas: através da inobservância absoluta, resultando na fome; ou da inobservância relativa, resultando na desnutrição. De uma forma ou de outra, isto é, resultando fome ou desnutrição haverá violação do direito humano e fundamental à alimentação adequada.

Ao contrário do que muitos pensam apenas $10 \%$ das mortes por falta de alimentação (fome) são resultados de conflitos armados, catástrofes naturais ou condições climáticas excepcionais; os outros $90 \%$ são vítimas da falta de acesso a uma alimentação adequada de forma crônica e por longo tempo, fundamentalmente estão ligadas à injustiça social, exclusão política, econômica e discriminatória (ONU - folheto informativo $\mathrm{n}^{\mathrm{o}} 34, \mathrm{p} .1$ )

A fome e a desnutrição permanecem, neste início de século, como um desafio a ser enfrentado pela comunidade internacional. Na Declaração do Milênio aprovada pela Assembleia Geral das Nações Unidas em 2000, os Estados se comprometeram a reduzir pela metade até o ano de 2015 o número de pessoas vítimas da fome. Em 2004 a FAO aprovou as diretrizes voluntárias em apoio à realização progressiva do direito a uma alimentação adequada no contexto da segurança alimentar nacional, orientando os Estados para a implementação de programas e projetos visando à garantia desse direito.

Segundo pesquisa realizada pela Organização das Nações Unidas para a Agricultura e a Alimentação (FAO, 2014), suas últimas estimativas indicam uma redução contínua na fome a nível mundial, tendo em torno de 805 milhões de pessoas cronicamente subalimentadas no período de 2012-2014, o que significa uma diminuição de mais de 100 milhões na última década e de 209 milhões se comparado ao período outrora pesquisado de 1990-1992 que era de 1,014 bilhão de pessoas. A América Latina reduziu de 60,3 milhões em 1990-1992 para 29,5 milhões em 2012-2014 representando mais de 50\% de diminuição de pessoas subalimentadas. Entretanto, muito há que se fazer ainda, pois uma a cada nove pessoas de todo o mundo carecem de alimentos suficientes para levar uma vida digna. A pesquisa evidencia, ainda, que a imensa maioria desta população subalimentada, em torno de 
791 milhões em 2012-2014, vive em países em desenvolvimento.

Dentre os documentos internacionais que melhor define e conceitua o conteúdo axiológico do direito à alimentação adequada é a observação geral $\mathrm{n}^{\circ} 12$ do Comitê de Direitos Econômicos, Sociais e Culturais do Pacto Internacional (PIDESC-ONU), que teve como objetivo, dentre outros, identificar questões imprescindíveis para o atendimento ao direto à alimentação adequada, principalmente no que tange ao distanciamento aos padrões estabelecidos no artigo $\mathrm{n}^{\circ} 11$ do PIDESC e a realidade constatada nos diversos países.

Tratou dos temas como: adequação e sustentabilidade da disponibilidade dos alimentos e do acesso a eles; obrigações e violações; aplicação no plano nacional; referências e marco legal; monitoramento; recursos e responsabilidades; obrigações internacionais, Estados-parte, Estados e as organizações internacionais, e, Nações Unidas e outras organizações internaciona is.

Desta forma, tornou-se o documento mais abrangente na proteção do direito à alimentação adequada. Em seu item 14 e 15 dispõe que os Estados Partes devem cumprir, como em qualquer outro direito humano, três tipos de níveis de obrigações; as de respeitar, proteger e realizar o direito humano à alimentação adequada. Assim, a obrigação de respeitar impede a adoção de quaisquer medidas que impeça o acesso à alimentação; a obrigação de proteger encerra o dever de assegurar que empresas ou indivíduos não privem as pessoas do acesso à alimentação; a obrigação de satisfazer trata de dois aspectos: 1. o Estado deve promover ações destinadas a fortalecer e garantir o acesso das pessoas aos recursos e meios para uma vida digna, incluída a segurança alimentar, bem como; 2 . sempre que o individuo ou grupo esteja impossibilitado, por razões que escapem ao seu controle, do acesso à alimentação adequada, o Estado tem obrigação de realizar (efetivar) esse direito diretamente. Esta obrigação também se aplica as pessoas que são vítimas de catástrofes naturais ou de outra índole.

No Brasil, o valor constitucional do direito à alimentação adequada consta do art. $6^{\circ}$ da Constituição Federal com a redação dada pela Emenda Constitucional n. 64, de 2010, sendo positivado, infraconstitucionalmente, desde a edição da Lei $n^{\circ} 11.346 / 2006$ que criou o Sistema Nacional de Segurança Alimentar e Nutricional (SISAN) em conformidade com os ditames do ordenamento jurídico internacional como analisado alhures.

Destarte, no plano interno o direito humano à alimentação adequada é um direito fundamental, e, similar ao ordenamento jurídico internacional tem como fundamento a dignidade da pessoa humana, atraindo todo sistema de proteção e eficácia dos direitos fundamentais. É o que dispõe o legislador no artigo $2^{\text {o }}$ da lei $n^{\circ} 11.346 / 06$, ao afirmar que "a alimentação adequada é direito fundamental do ser humano, inerente à dignidade da pessoa 
humana e indispensável à realização dos direitos consagrados na Constituição Federal [...]”, reconhecendo, ainda, as características da indivisibilidade, interdependência e interrelacionariedade dos diretos humanos, e que "[...] deve o poder público adotar as políticas e ações que se façam necessárias para promover e garantir a segurança alimentar e nutricional da população".

Diante de todo exposto, fica evidente a necessária atuação estatal através de todos seus poderes/funções, Legislativo, Executivo e Judiciário na garantia da efetivação/concretização do direito humano e fundamental à alimentação adequada. Cabe destacar, que o poder judiciário desempenha um papel fundamental na proteção desse direito, pois é o garante último dos direitos humanos de um país, sendo acionado quando necessário a garantir o cumprimento das normas internas e internacionais de proteção aos direitos dos cidadãos.

Nesse sentido, Flávia Piovesan (2008, p. 400):

Sob a ótica normativa internacional, está definitivamente superada a concepção de que os direitos sociais, econômicos e culturais não são direitos legais. A idéia da não-acionabilidade dos direitos sociais é meramente ideológica e não científica. São eles autênticos e verdadeiros direitos fundamentais, acionáveis, exigíveis e demandam séria e responsável observância. Por isso, devem ser reivindicados como direitos e não como caridade, generosidade ou compaixão.

Portanto, toda pessoa ou grupo, vítimas de uma violação do direito à alimentação adequada devem ter acesso a recursos judiciais efetivos, e de serem reparadas adequadamente, através de restituição, compensação, satisfação e garantias de que essas violações não se repetirão. Na maioria dos países os tribunais, incluídas as cortes supremas e as cortes constitucionais, salvaguardam os direitos humanos e oferecem recursos quando de suas violações. Os tribunais internos conhecem cada vez mais casos relacionados com o direito à alimentação (ONU - folheto informativo $n^{\circ} 34$, p. 36).

\section{A ARGUMENTAÇÃo dAS PARTES ENVOLVIDAS NO PROCESSO JUDICIAL E A POSSIBILIDAde JURÍdica DA PRESTAÇÃo AO DIREITO À ALIMENTAÇÃO}

Neste ponto do presente artigo serão explicadas, de forma detalhada, quais são os argumentos que podem ser utilizados pelo requerente e pelo requerido no processo judicial de obrigação de dar coisa certa, ou seja, o necessário para a alimentação e sobrevivência do autor 
e sua familia. É oportuno ressaltar que também serão formuladas críticas e comentários a cada uma das razões que serão dissertadas adiante.

\subsection{A possibilidade de bloqueio de verbas públicas para cumprimento de ordem judicial que contempla direito fundamental}

A Administração Pública Federal representada em juízo pela Advocacia Geral da União, a Administração Pública Estadual representada em juízo pelos Procuradores Estaduais e a Administração Pública Municipal representada em juízo pelos Procuradores Municipais vem, corriqueiramente, por meio de algumas razões, tentando se eximir do cumprimento das prestações envolvendo direitos fundamentais. É claro que o presente trabalho respeita o direito de defesa dos nobres entes federativos, porém, ao negar o cumprimento dos direitos consagrados na Constituição Federal, ultrapassa qualquer tipo de debate razoável, alcançando o status de um verdadeiro genocídio. Isso muito facilmente se explica com as ponderações que serão explicitadas a seguir as quais, em sua maioria, são repetidas como mantras jurídicos nos recursos encontrados nos tribunais pátrios.

A primeira e mais comum argumentação que é utilizada pelo Estado (Termo aqui utilizado para se referir aos entes federativos em geral) é que efetivamente cumpre as medidas relativas ao cumprimento dos direitos fundamentais, sendo o bloqueio de verbas públicas algo fora do razoável. Como é sabido é exaustiva jurisprudência que autoriza o sequestro de rendas públicas para situações inerentes a saúde e a vida. Cabe ressaltar que a tentativa inicial, no caso do direito a alimentação, é entregar coisa sabida e certa, no caso os alimentos mínimos à vida, sendo que a execução recai em primeiro sobre a coisa e, subsidiariamente, sobre o dinheiro para adquiri-la.

Não sendo respeitada a ordem do magistrado para a entrega da coisa que é alvo da discussão do processo judicial, deverão ser adotadas outras medidas, como as encontradas no artigo 461 do Código de Processo Civil:

Art. 461. Na ação que tenha por objeto o cumprimento de obrigação de fazer ou não fazer, o juiz concederá a tutela específica da obrigação ou, se procedente o pedido, determinará providências que assegurem o resultado prático equivalente ao do adimplemento.

$\S 5^{\circ}$. Para a efetivação da tutela específica ou a obtenção do resultado prático equivalente, poderá o juiz, de ofício ou a requerimento, determinar as medidas necessárias, tais como a imposição de multa por tempo de atraso, busca e apreensão, remoção de pessoas e coisas, desfazimento de obras e impedimento de atividade nociva, se necessário com requisição de força policial. 
Com a interpretação adequada do dispositivo supracitado, ou seja, utilizando uma compreensão exemplificativa e não taxativa, o requerente pode sim solicitar o bloqueio dos valores para a prestação da coisa necessária para a manutenção da vida.

Muitos sustentam a tese que ao receber salário, seja pelo trabalho ou o salário mínimo indicado no artigo 203, IV da Constituição Federal, este último conferido para pessoas que provem que não possuem maneiras de se prover, acabaria por derrubar a argumentação aqui apresentada, ledo engano. Ao afirmar que o governo presta salário mínimo, por meio da assistência social, aos que não tem condições de se manter e que, com isso, teria cumprido seu papel, acabam por esquecer o apregoado no artigo $6^{\circ}$, inciso IV, da própria Constituição Federal (1988) que define que deve ser prestado:

IV - Salário mínimo, fixado em lei, nacionalmente unificado, capaz de atender a suas necessidades vitais básicas e às de sua família com moradia, alimentação, educação, saúde, lazer, vestuário, higiene, transporte e previdência social, com reajustes periódicos que the preservem o poder aquisitivo, sendo vedada sua vinculação para qualquer fim;

Será que o salário mínimo atual, seja qual for sua base de referência, atende efetivamente todas as necessidades ali descritas? Será que, sendo muito otimista, com 800 reais por mês, um trabalhador brasileiro consegue prover moradia, alimentação, educação, saúde, entre outros aspectos relevantes de sua vida social? Já é um verdadeiro absurdo sendo que não está sendo nem discutida a extensão desses direitos aos seus familiares.

É compreendido que o Estado tem normas que protegem seus atos, inclusive se amparando de dispositivos legais para a não concessão dos direitos fundamentais consagrados ao cidadão. Ocorre que, como já muito debatido nos tribunais pátrios, havendo duas normas de mesma hierarquia, que, inicialmente, estão colidindo entre si, caberá ao magistrado, em sua interpretação eleger qual das duas tem maior prevalência: a que protege as verbas do Estado de medidas de sequestro ou a que protege o direito à alimentação como direito fundamental? É óbvio que prevalece o último. Muitos casos, acerca de outros direitos fundamentais, já foram decididos nas cortes superiores, assim como no Supremo Tribunal Federal:

AGRAVO REGIMENTAL EM AGRAVO DE INSTRUMENTO. CONSTITUCIONAL. DIREITO À SAÚDE. MEDICAMENTOS. FORNECIMENTO A PACIENTES CARENTES. OBRIGAÇÃO DO ESTADO. I - O acórdão recorrido decidiu a questão dos autos com base na legislação processual que visa assegurar o cumprimento das decisões judiciais. Inadmissibilidade do RE, porquanto a ofensa à Constituição, se existente, seria indireta. II - A disciplina do art. 100 da CF cuida do regime especial dos precatórios, tendo aplicação somente nas hipóteses de execução de sentença condenatória, o que não é o caso dos autos. Inaplicável o dispositivo constitucional, não se verifica a apontada violação à Constituição Federal. III - Possibilidade de bloqueio de valores a fim de assegurar o fornecimento 
gratuito de medicamentos em favor de pessoas hipossuficientes. Precedentes. IV -Agravo regimental improvido." (AI

553712 AgR, STF, $1^{\text {a }}$. T., Relator Min. Ricardo Lewandowski, julgado em

19/05/2009, DJe - 104 DIVULG 04-06-2009 PUBLIC 05 - 06 - 2009

EMENT VOL- 02363-09 PP - 01777 RT v. 98, n. 887, 2009, p. 164 - 167).

Outra decisão que caminha pela mesma esteira é observada em decisão da segunda turma do mesmo tribunal:

1. RECURSO. Extraordinário. Inadmissibilidade. Fornecimento de medicamentos. Bloqueio de verbas públicas. Direito à saúde. Jurisprudência assentada. Art. 100, caput e parágrafo $2^{\circ}$ da Constituição Federal. Inaplicabilidade. Ausência de razões novas. Decisão mantida. Agravo regimental improvido. Nega-se provimento a agravo regimental tendente a impugnar, sem razões novas, decisão fundada em jurisprudência assente na Corte. 2. RECURSO. Agravo. Regimental. Jurisprudência assentada sobre a matéria. Caráter meramente abusivo. Litigância de má-fé. Imposição de multa. Aplicação do art. 557, § $2^{\circ}$, cc. arts. 14, II e III, e 17, VII, do CPC. Quando abusiva a interposição de agravo, manifestamente inadmissível ou infundado, deve o Tribunal condenar o agravante a pagar multa ao agravado. (AI 597182 AgR, STF, 2a. T., Rel.: Min. Cezar Peluso, julgado em 10/10/2006, DJ 06-11-2006 PP-00042 EMENT VOL-02254-07 PP-01384 RNDJ v. 8, n. 86, 2007, p. 73-75).

Além disso, cabe mais uma vez frisar, que a maior parte das decisões judiciais que ordenam o cumprimento da obrigação de fornecimento de coisa para prestação de direito fundamental não são respeitadas, tendo as buscas e apreensões se tornado infrutíferas. O Estado estando recalcitrante no descumprimento das constantes ordens judicial para o cumprimento dessas obrigações não pode ter seu argumento sustentado.

\subsection{A solidariedade da União, Estados, Distrito Federal e Municípios na prestação dos direitos fundamentais}

Um dos fenômenos mais interessantes encontrados nas peças de defesa dos entes federativos, quando formam litisconsórcio passivo em um processo judicial que discute a prestação de direito fundamental, é a tentativa da desvinculação total de responsabilidade indicando que quem deve responder por tal obrigação é outro ente público. Para explicar de uma forma clara e simples o que seus representantes tentam fazer em juízo é dizer que a responsabilidade deve ser imputada a outro e aquele, que acabara de ser indicado, designará um terceiro e este utilizará a mesma argumentação com outro, sucessivamente, configurando um verdadeiro jogo de empurra-empurra. Infelizmente, quem está do outro lado desta demanda judicial é um cidadão, cuja vida corre sérios riscos por não ter o que comer. 
Por mais que as nobres procuradorias defendam com ardor essa alegação, suas teses não merecem resguardo. Em matéria sumulada no Tribunal de Justiça do Estado do Rio de Janeiro, a solidariedade dos entes federativos na materialização do direito subjetivo é bem clara e solidificada, observa-se:

\section{SÚMULA 65}

Deriva-se dos mandamentos dos artigos 6. ${ }^{\circ}$ e 196 da Constituição Federal de 1988 e da Lei n. ${ }^{\circ}$ 8.080/90, a responsabilidade solidária da União, Estado e Municípios, garantindo o fundamental direito à saúde e consequente antecipação da respectiva tutela.

Ademais, ao consultar a Lei 11.346, de 15 de setembro de 2006, pela qual foi criado o Sistema de Segurança Alimentar e Nutricional (SISAN), é encontrado no artigo $7^{\circ}$, que a prestação do direito humano à alimentação, por meio desse sistema, deverá ser cumprido pela União, Estados, Distrito Federal e Municípios, além dos órgãos inerentes a essa matéria.

Assim, não é possível que determinado ente federativo se esquive do cumprimento da obrigação de fornecer em se tratando de direito à alimentação.

\subsection{A necessidade da concessão de tutela}

Verificando que o direito à alimentação está inerentemente ligado a manutenção da vida de uma pessoa e com a morosidade para a execução dos atos de serventia nos tribunais brasileiros uma questão que deve ser alvo de comentários é a concessão da tutela antecipada em favor do requerente. Constantemente os magistrados pátrios solicitam o cumprimento do direito seguindo as seguintes etapas (Em caso de obrigação de dar coisa certa ou incerta):

a) Inicialmente, o juiz solicita o cumprimento do direito fundamental em questão concedendo um prazo razoável para isso;

b) Sabendo que o requerido do item anterior dificilmente é cumprido, o juiz ordena busca e apreensão para que possa ser retido a coisa que é objeto da discussão;

c) Mais uma vez, na maior parte dos casos, o mandado de busca e apreensão retorna negativo, ou seja, não tendo seu cumprimento sido possível (De forma mais corriqueira pela falta da coisa a ser entregue). Neste caso apela-se para o bloqueio online de verba pública, realizado por meio do sistema do BACENJUD, que alcança todas as contas vinculadas ao ente federativo que não cumpriu a ordem judicial. Apenas após todo esse caminho é que será expedido mandado de levantamento da quantia bloqueada que, faltamente, estará depositada em uma conta judicial. 
Agora, voltando para a antecipação de tutela. Imagine quanto tempo leva todo esse tramite? Agora acrescente a isso as várias petições meramente procrastinatórias que são juntadas pela requerida. Como se não fosse o bastante, a movimentação das fases acima é apenas para poder retirar o valor que se precisa para que, posteriormente, possa finalmente ser utilizado para a compra dos alimentos necessários para o requerente e sua família. Quanto tempo será que demora toda essa verdadeira peregrinação? 30, 60, 90 dias? Será que uma pessoa, provavelmente já debilitada na hora de propor a ação, conseguiria resistir todos esses dias sem a ajuda tão necessitada? É claro, como luz solar, que a vida, ou seja, o maior bem jurídico tutelado pelo direito, não resistiria a essa verdadeira via crúcis.

Assim, por todos os argumentos aqui narrados, pela gravidade da discussão em tela, a urgência deve ser considerada para que, a tutela antecipada, deva ser concedida, sem qualquer motivo para hesitação.

\subsection{Do pagamento direto sem a necessidade de precatório}

Ante a necessidade dos alimentos para a preservação da saúde e, consequentemente, da vida do requerente, o Estado insiste em alegar que os pagamentos, por ele realizados, devem ser feitos por meio da regra geral do precatório, ou seja, por meio da formalização de requisição de pagamento de quantia líquida devida pela Fazenda Pública. Esse tipo de alegação, encontradas em alguns recursos interpostos pelos patronos das esferas do Poder Executivo, é algo que beira ao esgotamento do bom senso pela Administração Pública.

Requerer ao magistrado, em um processo judicial, que a condenação para o cumprimento dos direitos fundamentais, neste caso à alimentação, seja pago por meio de um precatório que não tem data certa para ser pago é de uma crueldade de provocar inveja aos mais 
perigosos criminosos. Dois são os motivos de tal espanto: o primeiro, com menor intensidade, é verificar que um cidadão, que muita das vezes sempre contribuiu com a Administração Pública como, por exemplo, o pagamento de tributos, não ter direito no momento mais delicado de sua vida. ${ }^{6} \mathrm{O}$ segundo motivo, esse sim mais grave, imporia ao requerente uma longa espera enquanto sua fome permitir ocasionando, fatalmente, o óbito do mesmo.

Não há que se falar em precatório, independente do valor da prestação não se caracterizar como pequeno, pois se trata de manutenção da saúde, da vida; é a sobrevivência de um ser humano que está sendo discutida. A Constituição da República Federativa do Brasil estabeleceu, nos parágrafos $1^{\circ}$ e $2^{\circ}$ do artigo 100 , exceções à regra geral do pagamento via precatório para situações como a discutida no presente trabalho, como deve ser observado no entendimento do Superior Tribunal de Justiça:

Resp.909752/RS - RECURSO ESPECIAL 2006/0270886-3. Relator(a) Ministro JOÃO OTÁVIO DE NORONHA. Órgão Julgador T2 SEGUNDA TURMA. Data do Julgamento 28/08/2007 - Data da Publicação/Fonte DJ 13/09/2007 p. 189.

PROCESSO CIVIL E ADMINISTRATIVO. RECURSO ESPECIAL. CUSTEIO DE MEDICAMENTO. DIREITO À VIDA E À SAÚDE. BLOQUEIO DE VALORES EM CONTAS PÚBLICAS. POSSIBILIDADE. ART. 461, 5, DO CPC. 1. A Constituição Federal excepcionou da exigência do precatório os créditos de natureza alimentícia, entre os quais se incluem aqueles relacionados à garantia da manutenção da vida, como os decorrentes do fornecimento de medicamentos pelo Estado. 2. É lícito ao magistrado determinar o bloqueio de valores em contas públicas para garantir o custeio de tratamento médico indispensável, como meio de concretizar o princípio da dignidade da pessoa humana e do direito à vida e à saúde. Nessas situações, a norma contida no art. 461, 5 , do Código de Processo Civil deve ser interpretada de acordo com esses princípios e normas constitucionais, sendo permitida, inclusive, a mitigação da impenhorabilidade dos bens públicos. 3 . Recurso especial provido.

6 Faz-se necessário ressaltar que, independente do cidadão ter contribuído ou não, ele é atingido pela Constituição Federal, ao que concerne a esses direitos. O exemplo do contribuinte foi utilizado para demonstrar, claramente, a falta de reciprocidade em âmbito da prestação e contraprestação. 
Não há que se falar em precatório, independente do valor da prestação não se caracterizar como pequeno, pois se trata de manutenção da saúde, da vida; é a sobrevivência de um ser humano que está sendo discutida. A Constituição da República Federativa do Brasil estabeleceu, nos parágrafos $1^{\circ}$ e $2^{\circ}$ do artigo 100 , exceções à regra geral do pagamento via precatório para situações como a discutida no presente trabalho, como deve ser observado no entendimento do Superior Tribunal de Justiça:

Resp.909752/RS - RECURSO ESPECIAL 2006/0270886-3. Relator(a) Ministro JOÃO OTÁVIO DE NORONHA. Órgão Julgador T2 SEGUNDA TURMA. Data do Julgamento 28/08/2007 - Data da Publicação/Fonte DJ 13/09/2007 p. 189.

PROCESSO CIVIL E ADMINISTRATIVO. RECURSO ESPECIAL. CUSTEIO DE MEDICAMENTO. DIREITO À VIDA E À SAÚDE. BLOQUEIO DE VALORES EM CONTAS PÚBLICAS. POSSIBILIDADE. ART. 461, 5, DO CPC. 1. A Constituição Federal excepcionou da exigência do precatório os créditos de natureza alimentícia, entre os quais se incluem aqueles relacionados à garantia da manutenção da vida, como os decorrentes do fornecimento de medicamentos pelo Estado. 2. É lícito ao magistrado determinar o bloqueio de valores em contas públicas para garantir o custeio de tratamento médico indispensável, como meio de concretizar o princípio da dignidade da pessoa humana e do direito à vida e à saúde. Nessas situações, a norma contida no art. $461,5^{\circ}$, do Código de Processo Civil deve ser interpretada de acordo com esses princípios e normas constitucionais, sendo permitida, inclusive, a mitigação da impenhorabilidade dos bens públicos. 3 . Recurso especial provido.

Deste modo, pelos motivos aqui aduzidos, não é cabível o argumento do Estado que sustenta a prestação dos direitos fundamentais por meio de pagamento por precatório judicial.

\subsection{Existência de política pública específica}

Um dos argumentos mais utilizados pelos juristas, que não concordam com a discussão via judiciário do direito à alimentação, é a existência de políticas públicas e aspectos normativos que, na visão destes, supririam a necessidade de alimentação dos cidadãos brasileiros, atingindo-os em sua generalidade. O que será demonstrado a seguir são as políticas e os aspectos normativos que, invocados pelos entes federativos, seriam utilizados como justificativa para se escusar da prestação desse direito fundamental.

A primeira norma jurídica alegada, em defesa dos requeridos, é a Lei 11.346, de 15 de setembro de 2006. Por meio dela foi criado o Sistema de Segurança Alimentar e Nutricional (SISAN) que tem como principal objetivo assegurar o direito a alimentação, dos 
seres humanos, com a devida qualidade e seriedade. Ao analisar calmamente seu conteúdo, são encontrados alguns aspectos interessantes, que devem ser abordados.

No artigo $2^{\circ}$ da referida lei, existe uma definição estabelecendo que a alimentação é direito fundamental do ser humano, ligada aos aspectos da dignidade da pessoa humana e que deve ser prestada pelo poder público, pelos meios necessários. Além disso, o parágrafo $2^{\circ}$ do mesmo dispositivo, foi taxativo ao indicar que a Administração Pública deve prover, respeitar e promover o direito humano à alimentação adequada, devendo garantir mecanismos para que esse direito possa ser exigido. Em um raciocínio simples, baseado no relutante comportamento do gestor público em cumprir essas medidas, procrastinando as demandas judiciais com recursos intermináveis, não parece que há um respeito da norma estabelecida pelo legislador, no que concerne ao sistema vigente desde 2006.

Também não deve ser acolhida a tese da existência de programas de transferência de renda como, por exemplo, o programa Bolsa Familia ou a instituição do Programa Fome Zero, ambos do Governo Federal. Conforme dados já mencionados no início do presente trabalho, mesmo com programas de transferência de renda nem todas as pessoas são contempladas, ao contrário, com a crise econômica que alcança o Brasil nos últimos anos a tendência é a realização cortes, cada vez mais profundos, atingindo diretamente programas tais sociais. Hoje são mais de sete milhões de cidadãos (dados indicados no início do presente texto) que passam fome no Brasil, isto deve ser prioridade ao se deparar com a negativa da prestação desse direito fundamental.

Assim, de forma clara, os requeridos devem fornecer os alimentos, independentemente de haver sido esgotada a vida administrativa e de existirem programas sociais oficiais (que deixaram mais de sete milhões de excluídos), sob pena de se tornarem sem efeito as normas da Constituição da República Federativa do Brasil as quais, por serem definidoras de direitos e garantias fundamentais, possuem aplicabilidade imediata, devendo o Poder Judiciário, constatada a recalcitrante inércia do Poder Executivo, forçar o cumprimento do artigo $5^{\circ}$, inciso XXXV daquela norma, sem que isto viole o preceituado no artigo $2^{\circ}$ da mesma.

\subsection{As teorias da reserva do possível e custos de direitos contra a teoria do mínimo existencial e o princípio da dignidade da pessoa humana}

Por fim, um dos argumentos mais importantes que devem ser trazidos a discussão é a contraposição da teoria dos custos de direitos e da reserva do possível sustentadas, 
exaustivamente, pelos entes federativos e, as teorias do mínimo existencial com apoio no princípio da dignidade da pessoa humana. Serão analisadas tais argumentações e levantados os principais pontos que devem ser levados em máxima consideração.

A teoria dos custos dos direitos, criada e desenvolvida pelos juristas norteamericanos Cass Sustein e Stephen Holmes, foi publicada no livro intitulado The Cost of Rights: Why Libert Depends on Taxes (1999). A tese defende que de forma semelhante ao que ocorre na teoria da reserva do possível, todos os direitos possuem certo custo financeiro para serem cumpridos e, por isso, o Estado pode se esquivar da prestação, mesmo em se tratado de direito fundamental. Ademais, os nobres juristas entendem que o Estado é que acaba sendo o responsável pelo pagamento das garantias e direitos fundamentais dos cidadãos o que tornaria impossível de se cumprir com o orçamento público por ele gerido.

Adiante, na mesma obra, defendem que nenhum dos direitos ou garantias fundamentais podem ser definidos como absolutos, pois dependeriam de uma análise temporal com base em argumentos e dados financeiros e sociais, ou seja, o que hoje pode ser considerado fundamental há anos atrás poderia ter uma outra classificação. Para reforçar sua exposição indicam que o direito à saúde, que hoje é considerado fundamental, não era assim classificado na época em que eram realizados por padres ou curandeiros.

Tal argumento é tão equivocado que beira o verdadeiro absurdo. Por mais que devam ser respeitadas as posições dos juristas, grande parte do orçamento que o Estado gere tem origem nas contribuições tributárias realizadas pelos administrados, periodicamente, por meio de uma verdadeira diversidade de tributos (Federais, Estaduais e Municipais). Portanto, quem está pagando pelo cumprimento do que é garantido pela carta magna é o próprio cidadão, ao realizar o pagamento dos tributos que são pagos para a Administração Pública gerenciar e que possa, quando necessário, assistir as pessoas mais necessitadas.

Ademais, ao negar a prestação do direito à alimentação, o Poder Executivo possui legitimidade processual passiva para que tal discussão possa ser levada para a análise e julgamento pelo Poder Judiciário. Como se não bastasse essa simples constatação, os criadores da teoria dos custos dos direitos ressaltam que, ao provocar o Poder Judiciário, e sendo obtida gratuidade de justiça, mais uma vez o Estado estaria sendo responsável pelo ônus de um direito garantido constitucionalmente. É imperativo ressaltar a falta de humanidade dos mesmos, pois, como frisado acima, quem realiza o pagamento do funcionamento dos serviços estatais são, em sua maior parte, contribuintes, por meio das obrigações tributárias. 
Observando a outra posição, a do requerente, vislumbra-se a teoria do mínimo existencial com apoio no que apregoa o princípio da dignidade da pessoa humana. Em uma primeira leitura a reserva do possível pode ser definida como um instrumento para garantir a prestação efetiva do mínimo necessário, pautado no estabelecido pela lista constitucional, para todos, principalmente os mais pobres e necessitados. Isso não só assegura a manutenção da vida humana, mas, também, cumpre os parâmetros indicados como razoáveis para se respeitar a dignidade da pessoa humana.

Os tribunais superiores, principalmente o Supremo Tribunal Federal, vêm adotando a teoria do mínimo existencial, afastando de pleno a teoria da reserva do possível, em se tratando dos direitos fundamentais encontrados nos artigos $5^{\circ}$ e $6^{\circ}$ da Constituição Federal. Finalmente, ao se valer do aspecto social em detrimento do aspecto meramente financeiro os magistrados e ministros acabam por consolidar o caráter de justiça social no país.

\section{A EQUIPARAÇÃO DO DIREITO À ALIMENTAÇÃO COM DIREITOS FUNDAMENTAIS PRESTADOS VIA PODER JUDICIÁRIO.}

Realizando uma análise que, por meio de analogia, deixa uma ponta de esperança para o futuro, pode ser visto pequeno rastro inicial que ajudará a tese aqui defendida a se tornar corriqueira (e com êxito) nos tribunais. Ao deliberar sobre a Apelação Cível número 200983020017756, publicada em 27 de maio de 2010, o Tribunal Regional Federal da $5^{\text {a }}$

Região criou uma nota-se uma abertura para que a tese, do direito a alimentação, se sustente:

PROCESSUAL CIVIL. ARRESTO. PEDIDO DE BLOQUEIO DE VERBAS PÚBLICAS. AQUISIÇÃO DE CESTAS BÁSICAS E PAGAMENTO DE ALUGUÉIS. ÍNDIOS. DIREITO À ALIMENTAÇÃO E À MORADIA. EXTREMA VULNERABILIDADE SÓCIO-ECONỔMICA DOS INTERESSADOS. URGÊNCIA. POSSIBILIDADE JURÍDICA DO PEDIDO. PRESENÇA DE INTERESSE PROCESSUAL. APELAÇÃO PROVIDA. REFORMA DA SENTENÇA QUE INDEFERIU LIMINARMENTE A PETIÇÃO INICIAL. PROSSEGUIMENTO DO FEITO. I - A jurisprudência pátria, no exercício da missão de compatibilizar os princípios constitucionais, tem aberto exceções à regra do art. $100 \mathrm{da} \mathrm{CF} / 88$ e do art. 730 do CPC, admitindo em determinadas circunstâncias, com base num juízo de ponderação, a possibilidade de bloqueio de recursos públicos com vistas a satisfazer obrigação de pagar indispensável à concretização de direitos fundamentais do cidadão. Precedentes do STJ e do STF. II - Se os Tribunais Superiores, inclusive o STF, que exerce o mis ter de guardiãomor da Constituição, autoriza o bloqueio de valores para ass egurar o fornecimento de medicamentos ou tratamentos médicos "como meio de concre tizar o princípio da dignidade da pessoa humana e do direito à vida e à saúde", pe la mesma razão se re vela possível a adoção de medida no presente caso, em que se postula o cumprimento de obrigação, pela 
FUNAI, de entrega de cestas básicas e de pagamento de aluguéis aos apelantes. Os dire itos à alimentação e à moradia vinculam-se igualmente aos dire itos à vidae à dignidade, revelando-se essenciais à sobre vivência digna dos cidadãos. São, portanto, tão fundamentais quanto o dire ito à saúde. (grifo nosso) III - Vale ressaltar que os índios mereceram tratamento especial do Constituinte, que lhe dedicou um capítulo inteiro na $\mathrm{CF} / 88$ (Capítulo VIII do Título VIII - art. 231 e 232). No presente caso, os apelantes ostentam posição de grave vulnerabilidade sócio-econômica, vez que foram expulsos de suas casas e aldeias por outros índios. Em outras palavras, foram excluídos pelos próprios excluídos, o que os situa na periferia da periferia da sociedade. Precisam, portanto, do urgente amparo estatal, direito esse que foi reconhecido em acórdão desta Turma, da lavra da DD. Desembargadora Federal Margarida Cantarelli (AC402280-PE), pendente de cumprimento. IV - Apelação provida, determinando a baixa dos autos à instância de origem, a fim de que se dê regular andamento ao presente feito com a consequente análise do pedido liminar.

É de suma importância ressaltar que, ao equiparar o direito à alimentação com outros direitos fundamentais, como a saúde e a vida, que encontram guarida, de forma corriqueira, nas decisões dos mais diversos tribunais, a possibilidade de uma judicialização efetiva e real da solicitação de sua prestação se torna sólida e palpável para que os cidadãos, que estão em estado de vulnerabilidade, possam ser abarcados por uma nova jurisprudência pacífica.

Ademais, é sempre importante lembrar também umas das principais características dos direitos fundamentais: a vinculatividade. Isso significa que os direitos fundamentais possuem poder de vinculação, ou seja, não são simples declarações às quais permitiriam escolha de sua prestação pelos poderes estatais ou particulares. Nas palavras do constitucionalista português José Joaquim Gomes Canotilho, em sua obra Direito Constitucional e Teoria da Constituição, essa vinculação tem um duplo efeito:

Tais direitos vinculam o legislador em dois sentidos. Primeiramente, criando mecanismos jurídicos com o objetivo de estabelecer limites à atuaçãodo poder estatal. As normas jurídicas editadas pelo Estado devem conter limitações à sua própria atuação. Em outras palavras, o poder estatal precisa estar limitado por disposições normativas por ele próprio editadas. Em segundo lugar, ele deve atuar no sentido de elaborar normas jurídicas que assegurem direito subjetivo ao titular do direito fundamental e imponham deveres jurídicos às demais pessoas e aos poderes públicos. ( CANOTILHO, 2002. p. 440)

Por isso, o Poder Público, ao tentar se eximir da responsabilidade da prestação do direito à alimentação, considerando-o impossível de ser cumprido, afronta gravemente o estabelecido pelo legislador, no texto constitucional, em sua teia de proteção ao ser humano e sua dignidade. 


\section{CONSIDERAÇÕES FINAIS}

Ao longo deste estudo buscou-se analisar a possibilidade da judicialização do direito à alimentação adequada através da construção de um novo pensamento, baseado nos processos judiciais de solicitação do cumprimento de direitos fundamentais sociais, em face da Administração Pública, que são necessários à sobrevivência dos solicitantes, levando-se em conta o princípio da igualdade.

Para tanto se analisou o direito à alimentação adequada sob o prisma dos direitos humanos internacionalmente reconhecidos nos diversos tratados internacionais da qual o Brasil é signatário. E ainda, a análise no ordenamento jurídico interno.

Verificou-se que o direito a alimentação é um direito humano reconhecido pelas normas internacionais de direitos humanos, tanto pelo sistema universal quanto no sistema regional. E, apesar da frequente afirmação da comunidade internacional para a importância do pleno respeito ao direito à alimentação adequada necessária à garantia da dignidade da pessoa humana (fundamento nuclear dos direitos humanos), permanece a existência de um abismo preocupante entre as normas fixadas no ordenamento jurídico internacional dos direitos humanos, v.g., o artigo 11 do Pacto Internacional dos Direitos Econômicos, Sociais e Culturais (PIDESC), e a situação reinante em muitas regiões do mundo.

No Brasil, verifica-se, infelizmente, que a maior parte dos gestores públicos não está preocupada em respeitar a norma elaborada pelo legislador. Diariamente casos e mais casos do mau uso do dinheiro público preenchem os grandes jornais e noticiários, deixando uma impressão que os padrões de defesa dos cofres públicos só vêm à tona quando é para conferir direitos fundamentais, claramente estabelecidos pela norma constitucional.

Constatou-se que, por maior que seja a tentativa do Poder Público em tentar abster-se do cumprimento dos direitos fundamentais dispostos nos artigos $5^{\circ}$ e $6^{\circ}$ da Constituição Federal, todos os argumentos narrados no texto em tela são, com certa facilidade, refutados pelas argumentações por ora apresentadas, sendo que as decisões dos tribunais superiores acolhem, atualmente, as razões do requerente que, nesta situação, é o cidadão. No caso do direito à alimentação o Poder Executivo não pode se esquivar da obrigação de fornecê-los devendo atuar no sentido de proteger os direitos fundamentais e não, como muito se verifica hoje em dia, se omitir ou se esquivar por meio de uma sucessão de recursos com todas as forças para não cumprir o estabelecido constitucionalmente. 
Com relação ao papel do Poder Judiciário nesse cenário a vinculação se torna mais intensa ainda, pois existe a necessidade de se comprometer buscando a efetivação dos direitos fundamentais. Se as decisões, que têm sido proferidas, atualmente, pelo judiciário seguem a marcha para garantir tantos outros direitos como, por exemplo, direito à saúde, direito à vida e vagas em creche (respeitando o apregoado pelo direito à educação) por qual motivo não podem ser elaboradas decisões concedendo, às pessoas que não tem o necessário para alcançar os nutrientes mínimos para sobreviver.

Verificou-se a possibilidade de judicialização para se garantir a efetivação do direito à alimentação adequada com base nas decisões dos Tribunais Superiores, inclusive do Supremo Tribunal Federal, que autorizam o bloqueio de valores para assegurar, por exemplo, tratamento médico ou medicamentos como formas de respeitar o princípio da dignidade da pessoa humana e o direito fundamental a vida. Assim, em respeito ao princípio da igualdade, onde todos têm os mesmos direitos ao acesso aos bens e serviços considerados essenciais, o direto à alimentação vincula-se de forma semelhante aos direitos à vida, à saúde e a educação, pois são direitos humanos e fundamentais, oriundos do fundamento da dignidade da pessoa humana. De forma acertada, portanto, deve o judiciário apreciar lesão ou ameaça a direito conforme dispõe a constituição federal para garantir o direito humano e fundamental à alimentação adequada.

\section{BIBLIOGRAFIA}

BRASIL. Constituição da República Federativa do Brasil de 1.988. Brasilia, DF, Senado, $1988 . \quad$ Disponível em: <http://www.planalto.gov.br/ccivil_03/constituicao/constituicaocompilado.htm>. Acesso em: 20 jun. 2015.

Código de Processo Civil Brasileiro. Brasilia, DF, 1973. Disponível em: < http://www.planalto.gov.br/ccivil_03/leis/L5869.htm>. Acesso em: 20 jun. 2015.

Decreto $\mathrm{n}^{\circ}$ 591, de 6 de julho de 1992. Atos Internacionais. Pacto Internacional sobre Direitos Econômicos, Sociais e Culturais, Promulgação. Diário Oficial [da] República Federativa do Brasil, Brasilia, DF, 07 jul. 1992. Disponivel em: <http://www.planalto.gov.br/ccivil_03/decreto/1990-1994/D0591.htm>. Acceso em 15 mai. 2015 .

. Lei $\mathbf{n}^{\mathbf{0}}$ 11.346, de 15 de setembro de 2.006. Cria o Sistema Nacional de Segurança Alimentar e Nutricional - SISAN com vistas em assegurar o direito humano à alimentação adequada e dá outras providências. Disponível em: 
<http://www.planalto.gov.br/ccivil_03/_ato2004-2006/2006/lei/111346.htm>. Acesso em 20 jun. 2015.

. O direito humano à alimentação adequada e o sistema nacional de segurança alimentar e nutricional. Brasilia: ABRANDH, 2013. Disponível em: < http://www.mds.gov.br/segurancaalimentar/publicacoes\%20sisan/d haasisan-miolo-03041.pdf /download>. Acesso em: 5 ago. 2015.

. Secretaria de Direitos Humanos da Presidência da República. Direito à alimentação adequada. Brasilia: Coordenação Geral de Educação em SDH/PR, Direitos Humanos, Secretaria Nacional de Promoção e Defesa dos Direitos Humanos, 2013.

. Tribunal de Justiça do Estado do Rio de Janeiro. Súmula $\mathbf{n}^{\mathbf{0}}$ 65. Direito à saúde, antecipação da tutela de mérito, responsabilidade solidária da união, estados e municípios. Rio de Janeiro, RJ, 2003. Disponível em: <http//portaltj.tjrj.jus.br/web/guest/sumulas-65>. Acesso em: 5 ago. 2015.

CANOTILHO, José Joaquim Gomes. Direito Constitucional e Teoria da Constituição. $6^{\mathrm{a}}$ edição. Coimbra: Almeidina, 2002.

FAO, FIDA y PMA. 2014. El estado de la inseguridad alimentaria en el mundo 2014. Fortalecimiento de un entorno favorable para la seguridad alimentaria y la nutrición. Roma, FAO, 2014. Disponível em: < http://www.fao.org/3/a-i4030s.pdf>. Acesso em: 12 ago. 2015.

FAO, IFAD and WFP. 2014.The State of Food Insecurity in the World 2014.Strengthening the enabling environment for food security and nutrition. Rome, FAO, 2014. Disponível em: < https://www.fao.org.br/download/SOFI_i.pdf>. Acesso em: 17 jun. 2015.

FAO. Food and Agriculture Organization of the United Nations. World Food Situation. FAO Food Price Index. Realese date: 09/07/2015. Disponível em: <http://www.fao.org/worldfoodsituation/foodpricesindex/en/>. Acesso em: 2 ago. 2015.

Federação das Indústrias do Estado de São Paulo (FIESP). Departamento de Agronegócio (Deagro). Boletins Informativos: IPCA Alimentos e Bebidas. Julho, 2015. Disponível em: $<$ http //az545403.vo.msecnd.net/uploads/2015/08/ipca-alimentos_jul15.pdf $>$. Acesso em 3 ago. 2015.

HOLMES, Stephen; SUSTEIN, Cass R. The Cost of Rights: Why Liberties Depends on Taxes. Nova York: W.W. Norron \& Company, 1999.

Instituto Brasileiro de Geografia e Estatística (IBGE). Pesquisa Nacional de Amostras de Domicílios (PNAD). Pesquisa Suplementar de Segurança Alimentar 2013. A Percepção das Famílias em relação ao acesso aos alimentos. Rio de Janeiro, 2014.

KLAUSNER, Eduardo Antônio. Comentário ao Verbete n. 241 da Súmula do TJRJ (sobre 'Reserva do Possível). Revista de Direito do TJ-RJ, v. 96, p. 153, 2014.

ONU. Comentário Geral número 12. Sobre o direito humano à alimentação adequada, artigo $11^{\circ}$ do Pacto. Comitê de Direitos Econômicos, Sociais e Culturais do Alto Comissariado de Direitos Humanos. Geneva, 1999. Disponível em: < 
http://www.unhchr.ch/tbs/doc.nsf/(Symbol)/3d02758c707031d58025677f003b73b9?Opendoc ument>. Acesso em: 5 ago. 2015.

Declaración Universal de Los Derechos Humanos. Adoptada y proclamada por la resolución 217 A (III) de la Asamblea General de las Naciones Unidas el 10 de diciembre de 1948. Disponible en: <http//unesdoc.unesco.org/images/0013/001394/139423por.pdf > Acceso el: 18 mayo. 2015.

. Oficina Del Alto Comissionamento para Los Derechos Humanos. El derecho a la alimentación adecuada. Folheto informativo $\mathrm{n}^{\mathrm{o}}$ 34. Disponível em: < http://www.ohchr.org/Documents/Publications/FactSheet34sp.pdf>. Acesso em: 3 ago. 2015.

PIOVESAN, Flávia. Dignidade humana e proteção dos direitos sociais nos planos global, regional e local. In: MIRANDA, Jorge; MARQUES DA SILVA, Marco Antonio. Tratado lusobrasileiro da dignidade humana. São Paulo: Quartier Latin, 2008, p. 400.

SILVA, Marcelo Lessa da. El derecho a una vivienda a la luz derecho internacional de los derechos humanos. In: Reflexiones sobre Derecho Latinoamericano: Estudios en Homenaje a la Professora Silva Nonna / Paulo Aragão; José Marco Tayah; Letícia Danielle Romano. Fortaleza - Buenos Aires: Expressão Gráfica e Editora, 2015.

Transparency International. The Global Coalition Against Corruption. Corruption Perceptions Index 2014: Results. Berlin: 2014. Disponível em: < https://www.transparency.org/cpi2014/results>. Acesso em: 3 ago. 2015. 